Nilai-Nilai Kehidupan... (Farida F.dan Ani E.) | 139

\title{
NILAI-NILAI KEHIDUPAN DALAM NOVEL DILAN, DIA ADALAH DILANKU TAHUN 1990 DAN IMPLEMENTASINYA PADA PEMBELAJARAN BAHASA INDONESIA
}

\section{(THE VALUES OF LIFE IN THE NOVEL OF "DILAN, DIA ADALAH DILANKU TAHUN 1990" AND ITS IMPLEMENTATION IN INDONESIA LANGUAGE LEARNING)}

\author{
Farida Fitriani dan Ani Endriani \\ IKIP Mataram \\ farida.fitriani@yahoo.com
}

Diterima; 26 Mei 2018; Direvisi: 15 Oktober 2018; Disetujui: 24 November 2018

\begin{abstract}
Abstrack
The purpose of this study is to describe values of the life in the novel of "Dilan, Dia Adalah Dilanku Tahun 1990" and its implementation in Indonesian language learning at MAN 1 Lombok. The type of research used is qualitative method. The data are collected in the study throughreading method by tapping and note-taking techniques. Data analysis technique uses semiotic reading model, namely heuristic and hermeneutic readings. The validity of the data in this study is tsted by using triangulation techniques by applying the intrarater and interrater principles.The values of life in the novel of "Dilan, dia adalah Dilanku Tahun 1990" is social, democracy and love valueamong teenagers in that time. The values of life that can be modeled are the positive values, while the negative ones can be used as learning to avoid or not fall into things that are harmful to ourselves or others. The implementation of the values of life in the novel of "Dilan, dia adalah Dilanku Tahun 1990 at MAN 1 Lombok Tengah" has three stages of learning planning, namely the initial stage, the core, and the end.
\end{abstract}

Key words: values of life, novel, implementation

\begin{abstract}
Abstrak
Tujuan penelitian ini adalah mendeskripsikan nilai-nilai kehidupan novel Dilan, Dia Adalah Dilanku Tahun 1990 dan implementasinya pada pembelajaran Bahasa Indonesia di MAN 1 Lombok Tengah. Jenis penelitian yang digunakan yaitu kualitatif. Pengumpulan data dalam penelitian menggunakan metode simak dengan teknik sadap dan catat. Teknik analisis data yang digunakan adalah model pembacaan semiotik, yakni pembacaan heuristik dan hermeneutik. Keabsahan data penelitian ini menggunakan teknik triangulasi dengan menerapkan prinsip intrarater dan interrater. Nilai-nilai kehidupan dalam novel
\end{abstract}


Dilan, Dia Adalah Dilanku Tahun 1990 adalah nilai sosial, nilai demokrasi, dan percintaan di karangan remaja pada masanya. Nilai-nilai kehidupan yang dapat diteladani adalah nilainilai positif, sedangkan nilai negatif dapat dijadikan pembelajaran agar terhindar atau tidak terjerumus ke hal-hal yang merugikan diri sendiri maupun orang lain. Implementasi nilainilai kehidupan dalam novel Dilan, Dia adalah Dilanku Tahun 1990 di MAN 1 Lombok Tengah memliki tiga tahap perencanaan pembelajaran yaitu, tahap awal, inti, dan akhir.

Kata kunci: nilai-nilai kehidupan, novel dan implementasi 


\section{Pendahuluan}

Remaja adalah masa peralihan manusia dari anak-anak menuju dewasa. Remaja saat ini dapat dikatakan memiliki inovasi dan pengetahuan terdepan. Akan tetapi, di sisi lain remaja juga mengalami degradasi moral, khususnya yang berhubungan dengan pergaulan.

Pergaulan remaja merupakan masa yang sangat penting, sangat kritis, dan rentan. Pada masa tersebut, terjadi proses pematangan baik itu pematangan fisik, maupun psikologis. Pencarian jati diri yang kuat akan eksistensinya dapat mendorong remaja untuk melakukan ekspresi diri secara terang-terangan. Jika manusia melewati masa remajanya dengan kegagalan, dimungkinkan akan menemukan kegagalan dalam perjalanan kehidupan pada masa berikutnya. Sebaliknya, jika masa remaja diisi dengan penuh kesuksesan, kegiatan akan produktif dan berhasil untuk menyiapkan diri memasuki tahapan kehidupan selanjutnya.

Salah satu bentuk aktivitas remaja agar tidak terjerumus ke hal negatif yaitu kegiatan mengapresiasi karya sastra. Karya sastra merupakan sarana atau wadah yang dapat dikatakan efektif untuk mencegah terjerumusnya seorang remaja menuju hal negatif. Melalui sastra, ekspresi diri yang berlebihan dapat disalurkan dalam bentuk yang baik dan positif. Karya sastra memiliki peran yang penting dalam perkembangan moral, sosial, dan psikologi. Beberapa di antaranya adalah penanaman, penumbuhan, dan pengembangan kepekaan terhadap norma-norma manusiawi; serta pengenalan dan rasa hormat terhadap tata nilai, baik dalam konteks individual maupun sosial.

Salah satu bentuk karya sastra adalah novel. Novel adalah karangan prosa yang mengandung rangkaian cerita kehidupan seseorang dengan orang di sekelilingnya dengan menonjolkan watak dan sifat setiap pelaku (KBBI V). Dalam hal ini, unsur intrinsik dan ekstrinsik novel dapat dijadikan contoh untuk kehidupan remaja. Unsur-unsur tersebut dipadukan dan dimiripkan oleh pengarang dengan kisah-kisah nyata sehingga tampak benar terjadi. Pada unsur ekstrinsik, dalam novel terdapat nilai-nilai kehidupan yang dapat diteladani, sedangkan nilai negatif dapat dijadikan pembelajaran agar dapat 
terhindar atau tidak terjerumus ke hal-hal negatif yang merugikan diri sendiri maupun orang lain. Pengenalan novel secara intensif dan efektif kepada remaja sangat penting dan krusial. Pengenalan tersebut diharapkan memunculkan nilainilai positif bagi penikmatnya sehingga mereka dapat memecahkan masalahmasalah sosial dengan mengambil hal-hal positif yang berkaitan dengan kehidupan remaja.

Pemilihan Novel Dilan, Dia Adalah Dilanku Tahun 1990 dilatarbelakangi oleh kepopuleran filmnya. Dengan dialihkannya novel dalam bentuk film dan diperani oleh tokoh-tokoh yang diidolakan oleh remaja, membuat novel tersebut banyak diminati. Nilai-nilai kehidupan Novel Dilan, Dia adalah Dilanku Tahun 1990 mempunyai nilai kehidupan positif dan negatif. Kedua nilai tersebut berkaitan dengan persahabatan, percintaan, dan demokrasi. Dalam novel ini, Milea seolah-olah menjadi seorang pengarang yang berinteraksi langsung dengan pembaca. Dilan dan Milea adalah tokoh utama dalam novel yang mencari kesenangan, menolak ketidaknyamanan, dan dorongan biologis.
Berdasarkan uraian di atas, peneliti akan melakukan analisis terhadap nilai-nilai kehidupan yang terdapat di dalam novel Dilan Dia Adalah Dilanku Tahun 1990 karya Pidi Baiq. Penelitian ini bertujuan untuk mendeskripsikan nilai-nilai kehidupan novel Dilan, Dia Adalah Dilanku Tahun 1990 dan implementasinya pada pembelajaran bahasa Indonesia di MAN 1 Lombok Tengah.

\section{Kerangka Teori}

Sugihastuti (2007: 81) mengemukakan bahwa karya sastra merupakan media yang digunakan oleh pengarang untuk menyampaikan gagasan-gagasan dan pengalamannya. Peran karya sastra adalah menghubungkan pikiran-pikiran pe-ngarang yang disampaikan kepada pembaca. Ratna (2014: 173) mengatakan bahwa karya sastra dapat dikatakan sebagai dunia dalam kata, dunia miniatur, dunia imajiner, bahkan artifisial. Noor (2011: 17) juga berpendapat bahwa sastra memiliki beberapa ciri, yaitu kreasi, otonom, koheren, sintesis, dan mengungkapkan hal yang tidak terungkapkan. 
Berdasarkan pendapat ahli tersebut, dapat disimpulkan bahwa karya sastra adalah media yang digunakan oleh pengarang untuk menyampaikan pesan berupa kata dalam fiksi. Karya sastra juga dapat merefleksikan pandangan pengarang terhadap berbagai masalah yang diamati di lingkungannya. Realitas sosial yang dihadirkan melalui teks kepada pembaca merupakan gambaran tentang berbagai fenomena sosial yang pernah terjadi di masyarakat dan dihadirkan kembali oleh pengarang dalam bentuk dan cara yang berbeda. Selain itu, karya sastra dapat menghibur, menambah pengetahuan, dan memperkaya wawasan pembacanya dengan cara yang unik, yaitu menuliskannya dalam bentuk naratif. Karya sastra dimaksud tersebut berupa novel.

Novel adalah bentuk karya sastra yang sekaligus disebut fiksi. Novel dapat mengemukakan sesuatu secara bebas, menyajikan sesuatu secara lebih banyak, lebih rinci, lebih detil, dan lebih banyak melibatkan permasalahan yang kompleks. (Nurgiyantoro, 2014: 11). Berdasarkan pernyataan tersebut, dapat disimpulkan bahwa novel termasuk karangan yang panjang dan berbentuk prosa dan mengandung rangkaian kehidupan seseorang dengan orang lain di sekelilingnya dengan menonjolkan watak dan sifat setiap pelaku. Sebuah novel merupakan sebuah totalitas yang bersifat artistik. Sebagai sebuah totalitas, novel mempunyai bagian-bagian, unsur-unsur, yang saling berkaitan satu dengan yang lain secara erat dan saling menggantungkan. Unsur-unsur tersebut adalah unsur intrinsik dan ekstrinsik.

Unsur intrinsik adalah unsur-unsur yang membangun karya sastra itu sendiri, sedangkan unsur ekstrinsik adalah unsurunsur yang berada di luar karya sastra itu. Walaupun secara tidak langsung mempengaruhi bangunan atau sistem organisme karya sastra, namun unsur ekstrinsiktidak ikut menjadi bagian di dalamnya. Unsur ekstrinsikterdiri atas keadaan subjektivitas individu pengarang yang memiliki sikap, keyakinan, dan pandangan kehidupan, biografi, keadaan lingkungan pengarang, seperti ekonomi, politik, dan sosial yang semuanya itu mempengaruhi karya yang ditulisnya. Unsur ekstrinsik berikutnya adalah psikologi, baik yang berupa psikologi pengarang, psikologi pembaca, maupun penerapan prinsip psikologi dalam karya. 
Unsur ekstrinsik tidak hanya berkaitan dengan keindahan bahasa dan kompleksitas jalinan cerita. Nilai atau sesuatu yang berhargadalam novel juga berupa pesan atau amanat yang dapat diterapkan dalam kehidupan. Wujudnya seperti yang dikemukakan di atas, berkaitan dengan masalah budaya, moral, agama, atau politik. Realitas pesan-pesan itu mungkin berupa pentingnya menghargai tetangga, tolong-menolong, perlunya kesetiaan pada kekasih, ketawakalan kepada Tuhan, dan sebagainya (Suherli, dkk. 2017: 109).

Penelitian terdahulu yang menganalisis psikologi tokoh utama Novel Dilan Dia Adalah Dilanku Tahun 1990 Karya Pidi Baiq adalah penelitian yang dilakukan oleh Raja Azillah (2017). Dari hasil penelitiannya, ditemukan dalam novel Dilan 1990 unsur id, ego, dan superego. Unsur psikologi id dalam novel umumnya mendeskripsikan keinginan tokoh Milea, seperti mendeskripsikan keingintahuan Milea terhadap sesuatu, mencari kesenangan, dan menolak ketidaknyamanan, serta dorongan untuk memenuhi kebutuhan biologis. Unsur psikologi ego dalam novel meng- gambarkan tentang pemembuatan keputusan dan pemenuhan kebutuhan id. Selanjutnya, unsur psikologi superego dikelompokkan ke dalam kelompok benar dan salah, kata hati yang menghukum perilaku yang salah, serta merintangi dorongan id. Unsur psikologi paling dominan yang ditemukan dalam novel Dilan Dia Adalah Dilanku Tahun 1990 adalah ego.

\section{Metode Penelitian}

Jenis penelitian ini adalah kualitatif yang berlandaskan pada filsafat postpositivisme. Jenis penelitian ini digunakan untuk meneliti kondisi objek yang alamiah (Sugiyono 2008: 15). Data dalam penelitian ini diperoleh dari Novel Dilan, Dia Adalah Dilanku Tahun 1990. Dalam hal ini, yang digunakan sebagai data adalah kata, dialog, kalimat, dan paragraf. Dengan kata lain, semua bentuk tulisan yang terdapat dalam novel digunakan sebagai data.

Metode pengumpulan data dalam penelitian ini adalah metode simak dengan teknik sadap dan catat. Metode simak dilakukan dengan membaca dan menyimak novel (Mahsun, 2011: 92). Teknik sadap dimaksudkan untuk 
menyadap penggunaan bahasa pada novel, baik berupa kata, dialog, kalimat dan paragraf, kemudian mencatat bentukbentuk yang relevan secara tertulis dari nilai-nilai kehidupan novel Dilan, Dia Adalah Dilanku Tahun 1990 karya Pidi Baiq.

Teknik analisis data yang digunakan adalah model pembacaan semiotik, yakni pembacaan heuristik dan hermeneutik. Pembacaan heuristik adalah telaah dari kata-kata maupun kalimat, sedangkan hermeneutik merupakan penafsiran atas totalitas karya sastra (Endraswara, 2011:66).

Keabsahan data yang digunakan penelitian ini adalah teknik tringulasi dengan menerapkan prinsip validitas intraraterdan interrater. Interarater yaitu cara membaca dan meneliti subjek penelitian secara berulang-ulang sampai mendapatkan data yang dimaksud. Selain itu, digunakan validitas interrater yaitu dengan cara mendiskusikan hasil pengamatan dengan teman sejawat yang dianggap memiliki kemampuan intelektualitas yang cukup bagus.

Berikut adalah langkah-langkah peneliti dalam menganalisis data agar terealisasikannya metode yang di- gunakan. Pertama, peneliti membaca secara teliti seluruh isi novel Dilan Dia Adalah Dilanku 1990 karya Pidi Baiq. Kedua, peneliti mengelompokkan atau mengklasifikasikan nilai-nilai kehidupan novel Dilan Dia Adalah Dilanku 1990 karya Pidi Baiq. Ketiga, peneliti menafsirkan nilai-nilai kehidupan dalam novel Dilan Dia Adalah Dilanku 1990 karya Pidi Baiq. Keempat, peneliti mengimplementasikan nilai-nilai kehidupan novel Dilan Dia Adalah Dilanku 1990 karya Pidi Baiq pada pembelajaran bahasa Indonesia Kelas XI MAN 1 Lombok Tengah. Kelima, peneliti mengambil simpulan penelitian.

\section{Pembahasan}

\subsection{Nilai-Nilai Kehidupan yang Terkandung dalam Novel Dilan Dia Adalah Dilanku Tahun 1990}
a. Sosial

Nilai sosial yang terdapat dalam novel Dilan 1990 adalah persahabatan. Persahabatan terlihat ketika Milea jalan menuju kantin bersama teman-temannya. Seperti kutipan berikut.

Dari kantin, sebelum masuk ke kelas, aku berpapasan dengan Dilan. Dia jalan bersama kawankawannya. Pasti baru datang dari warung Bi Eem. (hlm. 57) 
Pada saat Milea jatuh sakit, teman-teman kelasnya datang menjenguknya. Keadaan tersebut merupakan bentuk simpati, seperti kutipan berikut.

Di hari kedua aku sakit, beberapa kawan sekelas datang ke rumah untuk menjenguk aku. Nandan juga ikut. Kutemui mereka di ruang tamu karena aku masih bisa berjalan. Sekitku tidak parah-parah amat. Sat-satu dari mereka menyalamiku dan mengcapkan doa keselamatan.

(hlm.97)

Nilai persahabatan juga terlihat pada saat Milea mencari waktu untuk mengobrol berdua dengan Wati dan teman-temannya yang lain yang ingin ikut bergabung. Hal itu tampak dalam kutipan berikut.

Keinginanku bisa ke kantin dengan Wati, akhirnya bisa kesampaian. Di kantin, ada Nandan, Rani, dan Jenar ingin gabung makan satu meja dengan kami, tapi kubilang aku ada urusan dengan Wati. Untung mereka ngerti, kemudian pada duduk di meja lain.

(hlm. 61)

Pada saat Dilan berkumpul dengan teman-temannya untuk membuat rencana, Milea ingin mengajak Dilan pergi jalan-jalan. Kutipan berikut menjelaskan bahwa Dilan dapat menjelaskan ke teman-temannya dengan alasan yang baik agar mereka tidak kecewa, seperti kutipan berikut.

Aku tahu aku sudah melemahkan dirinya dan mungkin membuat kamu bertanya-tanya apakah aku bisa dianggap layak melakukan hal itu, tapi aku tidak bisa menunggu sampai aku bisa menggagalkan rencanaya. Aku yakin Dilan sadar, apa tujuan asli dari aku mengajaknya. Sebab waktu tadi kuajak jalan-jalan, kulihat dia senyum, tapi aku yakin pada saat yang sama dia juga bingung, karena harus memilih. Bahwa akhirnya dia lebih memilih jalan-jalan denganku. Aku gak tahu diabilang apa ke semua temannya. tapi aku yakin, Dilan bisa menanganinya dengan baik untuk tidak membuat kecewa kawan-kawannya.

(hlm. 237)

\section{b. Percintaan}

Kisah cinta antara Dilan dan Milea dapat dikatakan tersirat. Proses Dilan mendekati Milea dengan kata-kata dan tindakan lucu pada masanya bukan gombalan semata, seperti kutipan pada penggalan cerita berikut.

"Aku ramal, nanti kita bertemu di kantin."

(hlm. 20)

Ternyata ramalan Dilan salah karena Milea ada urusan dengan teman kelasnya. Kemudian Dilan menyampaikan surat yang berisi 
permohonan maaf sekaligus ramalan ke2 yang dititipkan ke Piyan, salah satu sahabat karib Dilan. Berikut isi suratnya.

Milea, ramalanku, kita akan bertemu di kantin. Ternyata salah. Maaf, tapi aku ingin meramal lagi: besok kita akan bertemu.

(hlm. 22)

Milea berpikir bahwa ramalan itu akan gagal lagi karena besok adalah hari Minggu, sambil bertanya-tanya sendiri dalam hati, seperti kutipan berikut.

Apa? Besok bertemu? Bukankah besok itu hari Minggu? Aku langsung bisa nebak: ramalannya sudah pasti gagal lagi. Bagaimana bisa bertemu, kalau tidak di sekolah?

(hlm.23)

Namun, ternyata ramalan Dilan benar. Dilan datang ke rumah Milea untuk menyampaikan surat undangannya yang isinya

\section{Bismillahirrahmanirrahim.}

Dengan nama Allah Yang Maha Pengasih dan Penyayang. Denganini, dengan penuh perasaan, mengundang Milea Adnan untuk sekolah pada: Hari Senin, Selasa, Rabu, Kamis, Jumat, dan Sabtu.' (hlm. 27)

Hal-hal sederhana seperti itulah yang membuat Milea dan juga para penikmat novel Dilan tersenyum. Oleh karena itu, banyak remaja yang mengidolakan tokoh Dilan.Semata-mata karena tindakan yang dilakukan Dilan tergolong unik untuk mendapatkan perhatian Milea. Kemudian, saat Dilan bertemu dengan Milea, Dilan mengatakan bahwa Milea cantik. Berikut kutipannya.

"Milea"

Aku diam. Tidak kutanggapi. "Kamu cantik," katanya, dengan suara yang pelan tanpa memandangku.

(hlm. 34)

Pada saat Dilan sengaja mengungkapkan perasaannya kepada Nandan di samping Milea, percakapan tersebut cukup membuat Milea salah tingkah dan teman-temannya tertawa. Berikut kutipannya.

Dia datangi meja kami dan menyapaku:

"Hei, Milea!"

"Hei, Dilan, " kujawab langsung meski grogi.

"Cuma nyapa," katanya. "iya, he he he. " jawabku.

"Eh, Yan" tiba-tiba Rani nanya ke Piyan. "Wati gak sekolah, ya?"

"Sakit katany," jawab Piyan. "kenapa?"

"Ada bukunya ketinggalan."

"Oh, ya, dah," jawab Piyan.

"Pulangnya nanti kuambil."

"Oke." 
Setelah makan bala-bala (semacam bakwan), Dilan pergi bersama kedua temannya, entah ke mana, mungkun ke kelas, tapi sebelum pergi, diasempat bicara keNandan: "kamu tau gak?"

"tau apa?" Nandan balik nanya.

"Aku mencintai Milea."

Nandan tersenyum sambil sekilas memandangku. Rani, Dito, dan Jenar pada ketawa. Mukaku pasti merah.

"Tapi, malu mau bilang," kata Dilan.

"itu, sudah bilang," kata Nandan.

Nandan ketawa kecil, tapi ada rasa kesalnya

"Aku, kan, bilang ke kamu, bukan ke dia."

"Dia denger, kan?" tanya Nandan.

"Mudah-mdahan."

(hlm. 42)

Selanjutnya kisah unik terdapat pada hari ulang tahun Milea. Setelah teman-temannya memberikan ucapan doa dan kado yang diberikan oleh Nandan, Dilan juga memberikan kado berupa TTS. Hal itu membuat Milea tertawa. Berikut kutipannya.

Selamat ulang tahun Milea. Ini hadiah untumu, Cuma TTS. Tapi sudah kuisi semua. Aku sayang kamu. Aku tidak mau kamu pusing karena harus mengisinya. Dilan!

(hlm. 72)

c. Politik

Nilai politik yang terdapat dalam novel Dilan, Dia Adalah Dilanku Tahun
1990 dapat ditemukan pada saat Nandan sebagai ketua kelas dan Milea didukung teman-temannya untuk menjadi pengurus kelas. Berikut kutipannya.

Di kelas, selain Nandan, ada juga Rani dan Agus, semuanya teman sekelas. Hal yang dibahas adalah tentang keinginan mereka untuk menunjuk aku menjadi sekretaris, dan sekaligus bendahara kelas 2 Biologi 3. Aku sih, oke saja. Bagiku, gampanglah itu.

(hlm. 22)

Diperankan juga oleh Anhar yang memanfaatkan kelompoknya demi kepentingan pribadi. Berikut kutipannya.
Menghancurkan citra kropsnya sendiri. memanfaatkan nama kelompoknya hanya untuk mendapatkan keuntungan sedikit dan dijadikan sebagai kendaraan untuk tujuan mendapat kepentingan pribadi.

(hlm.84 )

\subsection{Nilai Negatif dalam Novel Dilan, Dia Adalah Dilanku Tahun 1990 \\ Nilai-nilai negatif yang terdapat} dalam novel yang diperankan oleh Dilan pada saat upacara bendera, di antaranya Dilan bersembunyi untuk menghindari upacara bendera, kemudian ditemukan bersembunyi oleh guru BP dan akhirnya dia berdiri di depan. Peristiwa tersebut tidak patut untuk diteladani, tetapi dapat 
dijadikan pembelajaran agar dapat terhindar atau tidak terjerumus ke hal-hal negatif yang merugikan diri sendiri maupun orang lain, seperti kutipan berikut.

Sang Peramal itu ada di sana, berdiri di depan, menghadap ke arah kami, bersama dua kawannya. Berdiri di sana karena dibawa oleh guru BP, setelah berhasil ditemukan dari tempatnya sembunyi, untuk menghindar ikut upacara bendera.

(hlm. 31)

Anhar adalah teman Dilan satu geng. Namun, Anhar pernah ditahan polisi karena pernah melakukan kriminal yaitu merampas barang orang dan meresahkan masyarakat. Berikut kutipannya.

Anhar juga katanya pernah ditahan polisi karena melakukan tindakan kriminal, merampas barang orang dengan tindak kekerasan di jalan raya. Melakukan kasus kejahatan dan meresahkan masyarakat yang tidak bisa ditolerir.Memalukan! Menjijikkan! Tidak elegan!

Menghancrkan citra korpsnya sendiri. memanfaatkan nama kelompoknya hanya untuk mendapatkan keuntungan sedikit dan dijadikan sebagai kendaraan untuk tujuan kepentingan pribadi.

(hlm. 84)

Peristiwa negatif pun terjadi pada saat Dilan melanggar peraturan saat upacara. Pak Suripto menegur Dilan dan kemudian menamparnya. Dilan merasa tidak setuju dengan tindakan gurunya, kemudian Dilan memukul Pak Suripto secara bertubi-tubi. Hal tersebut merupakan nilai negatif yang tidak patut ditiru. Dengan kejadian tersebut, Dilan mendapatkan hukuman skorsing selama seminggu untuk merenungkan kesalahankesalahannya. Hal itu tampak dalam kutipan berikut.

Dilan ikut upacara bendera, tapi dia masuk di barisanku. Berdiri sejajar dengaku. Tentu saja itu melanggar peraturan. Harusnya dia berada di barisan kawan-kawannya.

Benar saja, tepat pada waktu Kepala Sekolah sedang pidato, Pak Suripto datang menegurnya. Tanpa kata-kata, Pak Suripto langsung menarik kerah belakang baju Dilan. Dia bermaksud narik Dilan untuk keluar dari barian kelasku.

Apa yang dilakukan Pak Suripto membuat Dilan nyaris terjengkang. Dilan berseru:

"Heh? Apa ini?"

“Apa?! Melawan?" tanya Pak Suripto.

"Ya! Aku melawan!" teriak Dilan cukup keras, sampai membuat semua orang menengok ke arah suara Dilan. Kepala Sekolah juga menghentikan pidatonya.

Pak Suripto menampar Dilan. Dilan balas menampar Pak Suripto. Sebelum Pak Suripto menampar lagi, Dilan keburu memukulnya dengan pukulan bertubi.

(hlm.167) 
Hal negatif juga terlihat pada saat Milea pergi jalan-jalan dengan Dilan hingga sore. Ibunya khawatir dan sempat menelpon sekolah, tetapi tidak ada jawaban. Ibunya menjadi marah karena Milea tidak meminta izin terlebih dahulu. Hal itu tampak dalam kutipan berikut.

Aku masuk dan kudapati ibu marah karena aku pulang telat. Marah sedikit, sih, tapi itu juga marah.

Kubilang terus terang bahwa aku habis jalan-jalan sama Dilan. Ibu bilang kalau pulang telat aku harus kabar dulu ke rumah.

(hlm. 216)

Tindakan negatif terdapat lagi saat Anhar menampar pipi Milea. Kemudian Dilan marah dan memukul Anhar, walaupun Anhar mencoba meminta maaf kepada Dilan dan Milea. Akan tetapi, Dilan tidak menghiraukannya karena terlanjur marah

"Dilan berantem!"

Hah? Dilan? Kok, ada Dilan? Berantem sama siapa? Aku bergegas menerobos kerumunan dan melihat Dilan sedang berantem dengan Anhar. "Dilan!" Aku teriak ke Dilan. Bersamaan dengan itu, datang beberapa guru yang berhasil menghentikan perkelahian.

(hlm. 314)

\subsection{Implementasi pada Pembelajaran Bahasa Indonesia}

Pengimplementasian nilai-nilai kehidupan dalam pembelajaran bahasa Indonesia padakelas XI MAN 1 Lombok Tengah dapat disesuaikan dengan kompetensi inti, kompetensi dasar, dan tujuan pembelajarannya. Adapun kompetensi dasar dalam rencana pembelajaran bahasa Indonesia sebagai berikut. Pertama, mengidentifikasi nilainilai kehidupan yang terkandung dalam kumpulan cerita yang dibaca dengan indikator capaian dapat memahami informasi tentang nilai-nilai kehidupan dalam teks cerita dan menemukan nilainilai kehidupan dalam cerita. Kedua, mendemonstrasikan salah satu nilai kehidupan yang dipelajari dalam cerita dengan indikator capaian dapat menentukan nilai kehidupan dalam teks cerita dan mendemonstrasikan nilai kehidupan dalam teks kehidupan.

Berdasarkan kompetensi dasar tersebut, nilai-nilai kehidupan yang terdapat dalam novel tersebut dapat diimplementasikan melalui rencana pembelajaran dengan tiga tahap, yaitu kegiatan awal, kegiatan inti, dan kegiatan akhir. Kegiatan awal dilakukan dengan beberapa langkah. Pertama, diberikan stimulus berupa cuplikan film pendek 
Dilan, Dia Adalah Dilanku Tahun 1990 guna untuk merangsang ingatan siswa. Kedua, siswa menyimak kompetensi dan tujuan pembelajaran yang akan dicapai dan manfaatnya dalam kehidupan seharihari. Ketiga, siswa mendiskusikan informasi berdasarkan cuplikan film dengan proaktif tentang keterkaitan pembelajaran sebelumnya dengan nilainilai kehidupan dalam novel Dilan, Dia Adalah Dilanku Tahun 1990. Kegiatan inti dilakukan dengan langkah-langkah berikut. Pertama, siswa membaca sinopsis novel "Dilan, Dia Adalah Dilanku Tahun 1990” Karya Pidi Baiq. Kedua, siswa bertanya jawab tentang nilai-nilai yang terkandung dalam novel tersebut dan memberi komentar tentang nilai-nilai kehidupan yang terdapat dalam novel tersebut. Ketiga, siswa berdiskusi dengan teman sebangku untuk mengidentifikasi nilai-nilai dalam sinopsis novel yang dibaca dan dihubungkan dengan kehidupan. Keempat, siswa mencoba menetukan dan menganalisis nilai-nilai kehidupan dalam sinopsis novel dan menuliskannya. Kelima, siswa secara berkelompok dengan teman sebangkunya untuk mempresentasikan hasil kerjanya dan siswa lain memberikan komentar serta memberikan masukkan atas penampilan temannya. Selanjutnya kegiatan akhir, siswa dapat membuat rangkuman atau simpulan terhadap nilai-nilai kehidupan pada cerita kemudian melakukan refleksi dan guru memberikan umpan balik terhadap proses dan hasil pembelajaran positif dan negatif dari novel Dilan, Dia Adalah Dilanku Tahun 1990.

\section{Penutup}

Nilai-nilai kehidupan dalam novel Dilan, Dia Adalah Dilanku Tahun 1990 yaitu persahabatan, percintaan dan demokrasi. Dari ketiga nilai-nilai kehidupan, tersebut terdapat nilai yang positif dan negatif. Nilai positif dalam novel dapat diteladani, sedangkan nilai negatif dapat dijadikan pelajaran agar siswa dapat terhindar atau tidak terjerumus ke hal-hal negatif yang merugikan diri sendiri maupun orang lain.

Pengimplementasian nilai-nilai kehidupan dalam pembelajaran bahasa Indonesia pada kelas XI MAN 1 Lombok Tengah dapat disesuaikan dengan kompetensi inti, kompetensi dasar, dan 
tujuan pembelajaran. Selanjutnya, disesuaikan juga dengan rencana pelaksanaan pembelajaran dengan tiga tahap, yaitu tahap awal, inti, dan akhir.

\section{Daftar Pustaka}

Azilah, Raja. (2017). Analisis Psikologi Tokoh Utama Nobel Dilan, Dia adalah Dilanku Tahun 1990 Karya Pidi Baiq.E-Jurnal. Tanjung Pinang: Universitas Maritim Raja Ali Haji.

Endraswara, Suwardi. (2011). Metologi Penelitian Sastra. Yogyakarta: CAPS.

Kamus Besar Bahasa Indonesia $V$. Aplikasi Luring Resmi Badan Pengembangan dan Pembinaan Bahasa, Kementerian Pendidikan dan Kebudayaan Republik Indonesia.

Mahsun. (2011). Metode Penelitian Bahasa. Jakarta: RajaGrafindo Persada.

Noor, Rohimah M. (2011). Pendidikan Karakter Berbasis Sastra. Jogyakarta: Ar-ruzz Media.

Nurgiyantoro, Burhan. (2015). Teori Pengkajian Fiksi. Yogyakarta: Gajah Mada Universiti Press.

Septiana, Lozi. dkk. (2017). Nilai-Nilai Kehidupan pada Novel Moga Bunda
Disayang Allah Karya Tere Liye. Jurnal Korpus. Volume I, 89--100.

Sugihastuti. (2007). Teori Apresiasi Sastra. Yogyakarta: Pustaka Pelajar.

Sugiyono. (2008). Metode Penelitian Pendidikan. Bandung: Alfabeta.

Suherli, dkk. (2017). Bahasa Indonesia SMA/MA/SMK.Pusat Kurikulum dan Perbukuan, Balitbang, Kemikbud.

Ratna, Nyoman Kutha. (2014). Peran Karya Sastra, Seni dan Budaya dalam Pendidikan Karakter. Yogyakarta: Pustaka Pelajar. 